\title{
Genetic Parameters of Postnatal Mortality in Danish Holstein Calves
}

\author{
M. Hansen, ${ }^{\star} † \ddagger$ P. Madsen, ${ }^{\star}$ J. Jensen, ${ }^{\star}$ J. Pedersen, $†$ and L. G. Christensen \\ *Danish Institute of Agricultural Sciences, \\ Dept. of Animal Breeding and Genetics, \\ Research Centre Foulum, \\ P.O. Box 50, DK-8830 Tjele, Denmark \\ †The Danish Agricultural Advisory Centre, \\ Udkaersvej 15, Skejby, 8200 Aarhus N, Denmark \\ $\ddagger$ The Royal Veterinary and Agricultural University, Dept. of Animal Science and Animal Health, \\ Grønnegårdsvej 2, DK-1870, \\ Frederiksberg C, Denmark
}

\begin{abstract}
The objective of this study was to estimate genetic parameters of postnatal mortality (PM) in dairy cattle. Data originated from 841,921 Danish Holstein calves. Four binary traits of mortality were considered: D1-14, D15-60, D61-180, and D1-180 with numbers indicating the period of risk in days after birth. The unadjusted frequency of D1-14, D15-60, D61-180, and D1-180 were $0.027,0.018,0.020$, and 0.066 , respectively. A linear sire-model was fitted to the data, and average information-REML was used to estimate (co)variance components. Estimates of direct heritabilities for the four mortality traits ranged from 0.001 to 0.008 but were all significant. D61-180 and D1-180 had the highest direct heritabilities. Maternal heritabilities were very low, ranging from 0.0002 to 0.0015 and significant for D1-14 and D1-180 only. The direct genetic correlation between D1-14 and D15-60, between D15-60 and D61-180, and between D1-14 and D61-180 was 0.73, 0.54, and 0.34, respectively. It indicates that different genes are responsible for early PM (D1-14) and late PM (D61-180). When D61-180 was treated as a different trait for females, males not transferred, and transferred males, the direct heritability was $0.004,0.008$, and 0.034 , respectively, but the direct genetic correlations between these three traits were very high. If transfers of calves are getting more common, the importance of including $\mathrm{PM}$ in a breeding program will increase, as the genetic variation of PM was considerably higher for transferred calves than for calves that were not transferred.
\end{abstract}

Received July 29, 2002.

Accepted October 16, 2002.

Corresponding author: M. Hansen; e-mail: morten.hansen2@ agrsci.dk.
(Key words: calf, mortality, heritability, genetic parameter)

Abbreviation key: AI-REML = average information
REML, PM = postnatal mortality.

\section{INTRODUCTION}

Postnatal mortality (PM) of calves is not only costly for dairy cattle farmers, but it is also a problem related to animal health and welfare. Concerns of animal health and welfare are increasing, and consequently, these aspects should be considered in future animal breeding strategies (Olesen et al., 2000). In Denmark, field recordings of mortality are available for all Danish cattle born after 1997. This offers new possibilities for monitoring and analyzing the mortality in the population. The availability of such information can be valuable when animal health and welfare is discussed. Many studies have analyzed environmental causes of PM (e.g., Perez et al., 1990; Olsson et al., 1993; Sivula et al., 1996; Losinger and Heinrichs, 1997). A problem is that environmental changes (e.g., management and housing) are generally not permanent. In contrast, improvement of the additive genotype of the calves is permanent. However, genetic improvements are only possible if additive genetic variation for PM exists. Few genetic studies of PM have been carried out (Erf et al., 1990 [dairy cattle]; Cundiff et al., 1986 [beef cattle]), but they were based on few animals. In a review by Shook (1998), it was concluded that more genetic and economic studies of calfhood diseases and calfhood mortality were needed for making decisions on the use of these traits in breeding programs. Gastrointestinal diseases are believed to be the most important causes of PM in the first month of age, but later (up to the sixth month of age), respiratory diseases become the most important causes of mortality (Agerholm et al., 1993; Menzies et al., 1996; Sivula et al., 1996). Therefore, it 
is likely that different genes might affect early and late PM. Different genes might also affect PM for males and PM for females, as they are often treated and raised differently. As Weller and Gianola (1989) have shown, maternal additive genetics effects are considerable for stillbirths, but another question is whether maternal additive genetic variation exists for PM. The objective of this study was to estimate the direct and maternal additive genetic variance for PM, to estimate the genetic correlation between early and late PM, and to estimate the genetic correlation between PM of females and PM of males. These parameters, together with the market and nonmarket value of PM (Olesen, et al., 2000), are important for deciding how PM eventually should be included in a breeding program. Additionally, the models for estimation of genetic parameters give important knowledge about the effect of some environmental factors affecting PM.

\section{MATERIALS AND METHODS}

\section{Data}

New legislation introduced in 1998 required Danish farmers to supply all living cattle with a unique identification and for all cattle to record the date of births, deaths, slaughters, and transfers between herds. Thereby, it is possible to follow all cattle from birth to death (or until they are exported). These records, and all other information concerning Danish cattle, are stored in the Danish Central Cattle Database. Records from all Holstein calves born from January 1998 to October 2000 that had survived $24 \mathrm{~h}$ after birth $(1,148,017$ records) were extracted from this database. Information on transfers, deaths, and slaughters from birth until $180 \mathrm{~d}$ after birth was available for all calves. The following editing procedures were carried out: records of calves with unknown dam, sire, or maternal grand-sire were omitted (229,980 records). Calves from herds with fewer than 50 data records were omitted $(42,817$ records). Records of triplets or more were omitted (547 records). Records of calves with dams younger than 21 mo of age at calving were omitted (94 records). Only calves with an AI-bull as sire and maternal grandsire were included. Moreover, these AI-bulls should have more than 10 records as sire or as maternal grandsire $(110,068$ records omitted). The final dataset consisted of 764,511 records.

Four mortality traits were defined based on different periods of risk: D1-14, D15-60, D61-180, and D1-180, where the numbers indicate the period of risk in days after birth. For each of these traits, only calves alive at the beginning of the period were included. Mortality was defined as a binary trait: if the calf died in the period of risk, it was given the value 1 ; otherwise it
Table 1. Number of records and mean mortality for all, male, and female calves in the final dataset.

\begin{tabular}{|c|c|c|c|c|}
\hline \multirow[b]{2}{*}{ Trait } & \multirow{2}{*}{$\frac{\text { Total no. }}{\text { All }}$} & \multicolumn{3}{|c|}{ Mean } \\
\hline & & All & Males & Females \\
\hline D1-14 & 764,511 & 0.0272 & 0.0307 & 0.0238 \\
\hline D15-60 & 696,397 & 0.0182 & 0.0204 & 0.0163 \\
\hline D61-180 & 681,782 & 0.0203 & 0.0243 & 0.0168 \\
\hline D1-180 & 715,308 & 0.0662 & 0.0778 & 0.0560 \\
\hline
\end{tabular}

was given the value 0 . Records of calves that were slaughtered or exported before the end of the period of risk were not included. In some herds, all or a large proportion of bull calves were exported. To avoid an artificially high proportion of mortality in these herds, all records on bull calves from herds in which more than $20 \%$ of the bull calves were exported in the period of risk were omitted.

The number of observations and mean for the four mortality traits in the final dataset are given in Table 1. In the final dataset, $14 \%$ of the calves were transferred within the country from one herd to another before 180 $\mathrm{d}$ of age. These calves were included in the analysis. The main part (98\%) of these transfers was bull calves, most of which were transferred from a dairy farmer to a specialized beef producer. In Denmark, calves are not allowed to be transferred before $14 \mathrm{~d}$ of age. The few calves transferred before $14 \mathrm{~d}$ of age were considered misreported and were set to $14 \mathrm{~d}$ of age. The main part of transfers was performed from 14 to $60 \mathrm{~d}$ of age. Fortysix percent of the transfers before $180 \mathrm{~d}$ of age were in the period from 14 to $30 \mathrm{~d}$, and $41 \%$ of the transfers were in the period from 31 to $60 \mathrm{~d}$ of age.

\section{Statistical Analyses}

The statistical analyses were carried out in two parts. First, a simple survival analysis was used to estimate the cumulative proportion of dead male and female calves. Secondly, comprehensive analyses with linear models were carried out to estimate (co)variance components and nongenetic effects.

Survival analysis. An overview of the cumulative proportion of dead calves from 1 to $180 \mathrm{~d}$ after birth was obtained by plotting the Kaplan-Meier estimate of the survival function (Kaplan and Meier, 1958). By using the nonparametric Kaplan-Meier method, the cumulative proportions were adjusted for censored observations (slaughtered and exported calves). The cumulative proportion of dead calves was defined as 1 minus the Kaplan-Meier estimate. The estimation was carried out with the LIFETEST procedure in SAS (1999), using all data before editing. Some calves (5132) were recorded as dead after $24 \mathrm{~h}$ from birth without recording 
the date of death. However, it was known that they died in the first week after birth. Although most of these calves probably died in the first days, they were given a random age from $d 1$ to 7 .

Linear models. Linear models were used for analysis of the edited data. When using least-squares procedures on discrete data, estimates of fixed effects are unbiased, but the accuracy of tests of significance depends on an adequate number of observations in each subclass (Harvey, 1982). Therefore, small subclasses of fixed effects were avoided.

The linear analyses consisted of six steps with six different models:

Test of fixed effects.

Univariate analyses of direct and maternal effects.

Trivariate analyses where the mortality traits were defined as different traits depending on the parity of the dam of the calf. Only parities one, two, and three were used.

Bivariate analyses of mortality in different periods of risk.

Bivariate analyses of mortality traits defined as different traits depending on the sex of the calf.

Trivariate analyses of D61-180 where mortality for females, males not transferred, and males transferred in the period from 14 to $60 \mathrm{~d}$ of age was defined as different traits.

Tests of fixed effects in step A were carried out using the GLM procedure in SAS (1999). The estimation of (co)variance components in steps B through $\mathrm{E}$ was carried out with the average information REML (AIREML) procedure (Jensen et al., 1997), which is included in the DMU-package (Jensen and Madsen, 1994). The AI-REML algorithm maximizes the restricted likelihood by use of the average of second derivatives and their expectations. It has been shown to have much faster convergence than EM (expectation maximization) and DF (derivative free) methods (Jensen et al., 1997).

A) Model A was applied as the initial model for all four mortality traits in step A:

Model A:

$$
\begin{aligned}
\mathrm{Y}_{\mathrm{ijklmnopqrst}}= & (\text { birthyear-birthmonth-region- } \\
& \text { sex })_{\mathrm{ijkl}}+(\text { transfer-transfermonth- } \\
& \text { sex } \left.)_{\text {nol }} \text { (included for D61-180 only }\right) \\
& +(\text { calvingage1-parity-twin-sex })_{\mathrm{qmpl}} \\
& +(\text { parity-calvingage2-calvinginter- } \\
& \text { val-sex })_{\mathrm{mrsl}}+\text { herd } \mathrm{t}_{\mathrm{t}}+\mathrm{e}_{\mathrm{ijkl} \text { nopqrst }} \\
& \text { where the combination of the effects } \\
& \text { denote the smallest subclass for } \\
& \text { these interactions, and } \\
\mathrm{Y}_{\mathrm{ijklmnopqrst}}= & \text { the observation }(0 \text { or } 1) \text { of the mor- } \\
& \text { tality trait, birthyear }{ }_{\mathrm{i}}=\text { fixed effect }
\end{aligned}
$$

of year of birth, $\mathrm{i}=\{1998,1999$, $2000\}$,

birthmonth $_{\mathrm{j}}=$ fixed effect of month of birth, $\mathrm{j}=\{1$, $2, \ldots, 12\}$,

region $_{\mathrm{k}}=$ fixed effect of region of country, $\mathrm{k}=$ $\{1,2, \ldots, 10\}$,

$\operatorname{sex}_{1}=$ fixed effect of sex of calf $\{$ male, female\},

parity $_{\mathrm{m}}=$ fixed effect of the parity of the dam, $\mathrm{m}=\{1,2,3,4,5+\}$,

transfer $_{\mathrm{n}}=$ fixed effect of age in days when the calf is transferred, $\mathrm{n}=\{$ no transfer, 14-30, 31-60\}

transfermonth $_{0}=$ fixed effect of month of transfer, o $=\{1,2, \ldots, 12\}$,

$\operatorname{twin}_{p}=$ fixed effect of twin, $p=$ not twin, twin with a twin brother, twin with a twin sister $\}$,

calvingage $1_{\mathrm{q}}=$ fixed effect of age of dam in months at first calving, $q=\{21, \ldots, 37,38+\}$,

calvingage $2_{\mathrm{r}}=$ fixed effect of age of dam in months at second calving, $\mathrm{r}=\{<37,37-42$, $43-47,48-52,53+\}$,

calvinginterval $\mathrm{s}_{\mathrm{s}}=$ fixed effect of previous calving interval of the dam in days, $\mathrm{s}=\{$ no calving interval (1. parity), $<331$, $331-390, \ldots, 631-690,690+\}$,

herd $_{t}=$ fixed effect of herd, $t=\{1,2,3, \ldots$, $5714\}$, and

$\mathrm{e}_{\mathrm{ijklmnopqrst}}=$ residuals $\sim \mathrm{N}\left(0, \sigma^{2}\right)$ and independent.

The effect of herd was absorbed. The fixed effects (and their interactions), which were significant $(P<$ 0.05 ) for just one of the traits, were chosen and used for all traits in the following models. The effect of age at second calving and many of the interactions were not significant for any of the traits. The resulting fixed effects that were used in the models for estimating (co)variance components were birthyear-birthmonth-region-sex, calvingage1(parity), twin-sex, and calving interval. For the trait D61-180, the effect of transfertransfermonth was also included.

In matrix notation, the models used to estimate (co)variance components were as follows:

$$
\text { Model B: } \mathbf{y}=\mathbf{X b}+\mathbf{W h}+\mathbf{Z}_{1} \mathbf{s}+\mathbf{Z}_{2} \mathbf{m g s}+\mathbf{e}
$$

where $\mathbf{y}$ consisted of observations of D1-14, D15-60, D61-180, or D1-180. The number of these observations are as given in Table 1.

$$
\text { Model C: } \mathbf{y}_{\mathrm{i}}=\mathbf{X}_{\mathrm{i}} \mathbf{b}_{\mathrm{i}}+\mathbf{W}_{\mathrm{i}} \mathbf{h}_{\mathrm{i}}+\mathbf{Z}_{1} \mathbf{s}_{\mathrm{i}}+\mathbf{e}_{\mathrm{i}}, \mathrm{i}=\{1,2,3\} \text {, }
$$


where $\mathbf{y}_{\mathrm{i}}$ consisted of observations of D1-14, D15-60, D61-180, or D1-180 for calves with a first $(i=1)$, second $(\mathrm{i}=2)$, and third $(\mathrm{i}=3)$ parity dam. Data were transposed so that a record consisted of a dam with different fixed and different random effects for each parity. With this model, the effect of repeated observations from the same dam was giving in the environmental covariance, and the genetic association between PM of calves from dams with different parities was given in the genetic covariance. To model this, only one observation per parity could be used. Therefore, a randomly chosen twin was omitted for each pair of twins. For D1-14, the numbers of observations were $239,169,215,972$, and 138,149 for first, second, and third parities, respectively.

$$
\text { Model D: } \mathbf{y}_{\mathrm{i}}=\mathbf{X}_{\mathrm{i}} \mathbf{b}_{\mathrm{i}}+\mathbf{W}_{\mathrm{i}} \mathbf{h}_{\mathrm{i}}+\mathbf{Z}_{1} \mathbf{s}_{\mathrm{i}}+\mathbf{e}_{i}, \mathrm{i}=\{1,2\},
$$

where $\mathbf{y}_{\mathrm{i}}$ consisted of observations of D1-14 and D1560, D1-14 and D61-180, or D15-60 and D61-180. Model $\mathrm{D}$ used the same data as in Model B and consisted of the same effects for each trait. The only exception was that mgs was omitted.

$$
\text { Model E: } \mathbf{y}_{\mathrm{i}}=\mathbf{X}_{\mathrm{i}} \mathbf{b}_{\mathrm{i}}+\mathbf{W}_{\mathrm{i}} \mathbf{h}_{\mathrm{i}}+\mathbf{Z}_{1} \mathbf{s}_{\mathrm{i}}+\mathbf{e}_{\mathrm{i}}, \mathrm{i}=\{1,2\},
$$

where $\mathbf{y}_{\mathrm{i}}$ consisted of observations of D1-14, D15-60, D61-180, or D1-180 for female $(i=1)$ and males $(i=2)$.

$$
\text { Model F: } \mathbf{y}_{\mathrm{i}}=\mathbf{X}_{\mathrm{i}} \mathbf{b}_{\mathrm{i}}+\mathbf{W}_{\mathrm{i}} \mathbf{h}_{\mathrm{i}}+\mathbf{Z}_{1} \mathbf{s}_{\mathrm{i}}+\mathbf{e}_{\mathrm{i}}, \mathrm{i}=\{1,2,3\}
$$

where $\mathbf{y}_{\mathrm{i}}$ consisted of observations of D61-180 for females $(\mathrm{i}=1)$, males not transferred $(\mathrm{i}=2)$, and males transferred $(i=3)$.

In these models $\mathbf{X}, \mathbf{W}, \mathbf{Z}_{1}$, and $\mathbf{Z}_{2}$ were design matrices relating effects to observations. The fixed effects in the models were given in $\mathbf{b}$. Three random environmental effects were included in $\mathbf{h}$ : herd, herd-sex, and herdyear-season. Records were clustered to herd-year-season effects as described by Schmitz et al. (1991), with a maximum interval of $365 \mathrm{~d}$ and minimum desired cluster-size of 20 records. The random effects of sires of calves were given in $\mathbf{s}$, the random effects of sires of dams in $\mathbf{m g s}$, and the residuals in $\mathbf{e}$.

All random effects were assumed to be normally distributed and independent within each trait. The exception was model $\mathrm{B}$, in which covariance between $\mathbf{s}$ and mgs was assumed. A common relationship matrix was used for $\mathbf{s}$ and $\mathbf{m g s}$. In the multivariate analyses, covariance between random effects for different traits was assumed. The only exception was the residual effects in model $\mathrm{E}$ and $\mathrm{F}$, where no covariances were assumed, as the mortality traits were measured on different calves.

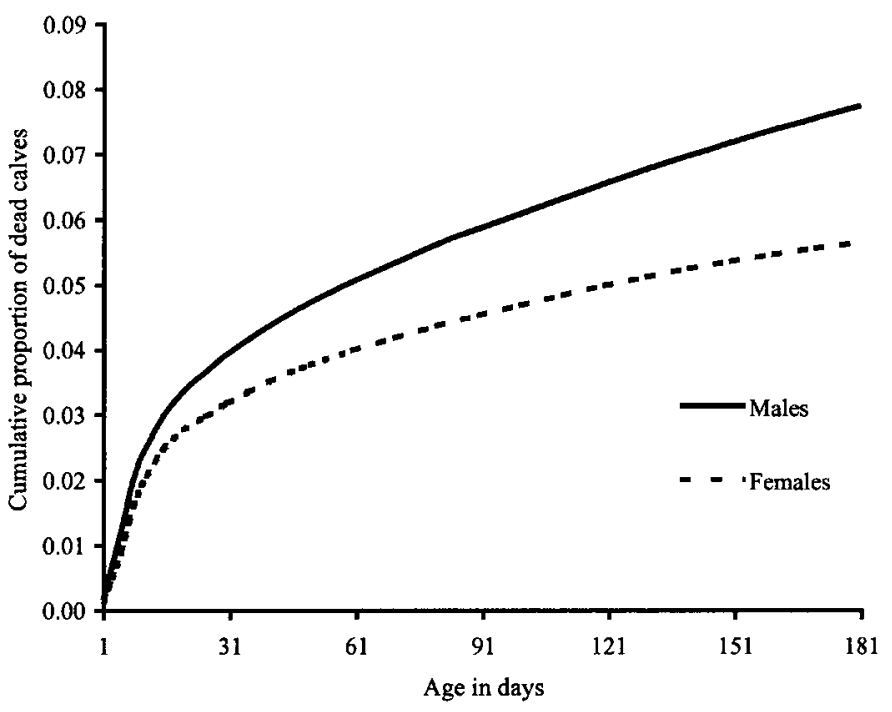

Figure 1. Estimated cumulative proportion of dead male and female calves from 1 to $181 \mathrm{~d}$ of age using all data before editing. The cumulative proportion was estimated as 1 - the Kaplan-Meier estimate.

The number of sires of calves and sires of dams was 1380 and 5615, respectively. Some of the sires (474) appeared both as sires of calves and sires of dams. This resulted in 6521 different sires with records. The relationship matrix for these sires was built by tracing their sires and dams as far as possible. This resulted in a relationship matrix containing 21,635 animals.

Estimates of heritabilities of direct and maternal effects and estimates of genetic correlations between direct and maternal effects were derived using the approach described by Manfredi et al. (1991b). The phenotypic variation used to derive the heritabilities was defined as the sum of all variance components in the model (including variance components for herd, herdsex, and herd-year-season). Variance ratios of herd, herd-sex, and herd-year-season were obtained by dividing the variance component with the phenotypic variation. Standard errors of heritabilities, variance ratios, and correlations were approximated by a first-order Taylor series expansion, using the average information matrix of the estimated (co)variance components. All estimates were considered significantly different $(P<$ 0.05 ) from the null hypothesis if they deviated more than 1.96 times their standard error. Heritabilities of binary traits depend on the frequency of the trait. To express heritabilities independently of the frequency, they were transformed to the underlying scale by the approximate formula proposed by Robertson in Dempster and Lerner (1950). Simulation studies have shown that this approximation works well but tends to overestimate heritabilities on the underlying scale when the 
Table 2. Estimates of genetic parameters from model B: phenotypic standard deviation (P), direct (D) heritability, maternal (M) heritability, and the correlation between the direct and maternal effects. ${ }^{1}$

\begin{tabular}{llllllr}
\hline & $\sigma_{\mathrm{P}}$ & \multicolumn{1}{l}{$\mathrm{h}_{\mathrm{D}(\mathrm{o})}^{2}$} & \multicolumn{1}{l}{$\mathrm{h}_{\mathrm{M}(\mathrm{o})}^{2}$} & $\mathrm{~h}_{\mathrm{D}(\mathrm{u})}^{2}$ & $\mathrm{~h}_{\mathrm{M}(\mathrm{u})}^{2}$ & \multicolumn{1}{c}{$\mathrm{r}_{\mathrm{D}, \mathrm{M}}$} \\
\hline $\mathrm{D} 1-14$ & 0.163 & $0.0029 \pm 0.0006$ & $0.0013 \pm 0.0005$ & 0.019 & 0.009 & $0.386 \pm 0.252$ \\
$\mathrm{D} 15-60$ & 0.134 & $0.0014 \pm 0.0004$ & $0.0002 \pm 0.0002$ & 0.012 & 0.002 & $0.242 \pm 0.491$ \\
$\mathrm{D} 1-180$ & 0.141 & $0.0077 \pm 0.0011$ & $0.0002 \pm 0.0003$ & 0.064 & 0.002 & $-0.060 \pm 0.425$ \\
$\mathrm{D} 1-180$ & 0.249 & $0.0072 \pm 0.0010$ & $0.0015 \pm 0.0006$ & 0.027 & 0.006 & $0.026 \pm 0.221$ \\
\hline
\end{tabular}

${ }^{1}$ Heritabilities are expressed on the observed scale (o) and the underlying scale (u).

frequency is low and the heritability is high (Van Vleck, 1972).

\section{RESULTS}

\section{Kaplan-Meier}

The cumulative proportion of dead calves from $\mathrm{d} 1$ to 181 had the highest increase in the first part of the period (Figure 1). This shows that the probability of death per day among calves was highest early in life. The age of some calves that died from $d 1$ to 7 was unknown, and the age was randomly assigned. The curve for the first week would probably be steeper in the first days if the exact age at death was known for these calves. Through the whole period the cumulative proportion increased more for males than for females. The cumulative proportion of dead calves at $180 \mathrm{~d}$ of age was 0.077 for males and 0.056 for females, which is almost identical to the unadjusted frequencies given in Table 1.

\section{Random Effects}

Heritabilities and genetic correlations. Estimates of heritabilities and genetic correlations between direct and maternal effects from the univariate analyses using model B are given in Table 2 . The estimates of the heritability of the direct effects were low but significantly different from 0 for all mortality traits. On the observable scale, the estimates of direct heritability of D1-14, D15-60, D61-180, and D1-180 were 0.003, $0.001,0.008$, and 0.007 , respectively. When transformed to the underlying scale, the heritability of D61180 (0.064) was considerably higher than for the other traits. Estimates of maternal heritabilities on the observable scale were very low, ranging from 0.0002 to 0.0015 and significant for D1-14 and D1-180 only. The maternal heritabilities, expressed on the underlying scale, were also very low, ranging from 0.002 to 0.009 . None of the estimated correlations between direct and maternal effects were significantly different from 0 . The estimates of the correlations between direct and maternal effects had high standard errors due to the structure of the data, where most of the bulls were either sires of calves or sires of dams. More accurate estimates of this correlation require data covering a longer time span.

In Table 3, the estimates of genetic parameters from model $\mathrm{C}$ are presented. In model $\mathrm{C}$ each mortality trait was treated as a different trait, depending on the parity of the mother. For all mortality traits, there was a very high genetic correlation $(>0.93)$ between PM of calves from dams in different parities. Within the mortality traits, only minor differences of heritabilities were found. However, the heritability of D61-180 was larger for calves from first parity than for calves from later

Table 3. Estimates of genetic parameters (par) from model C, in which mortality is defined as different traits depending on the parity of the dam: direct heritabilities on the observed scale in the diagonals and direct genetic correlations above the diagonals.

\begin{tabular}{lllcr}
\hline & & par 1 & par 2 & par 3 \\
\hline D1-14 & par 1 & $0.0028 \pm 0.0010$ & $0.967 \pm 0.101$ & $0.949 \pm 0.147$ \\
& par 2 & & $0.0046 \pm 0.0012$ & $0.998 \pm 0.126$ \\
& par 3 & \multirow{2}{*}{$0.0027 \pm 0.0011$} & $0.995 \pm 0.159$ & $0.0019 \pm 0.0008$ \\
D15-60 & par 1 & $0.0036 \pm 0.0012$ & $0.993 \pm 0.124$ \\
& par 2 & & $0.975 \pm 0.120$ \\
& par 3 & & & $0.0026 \pm 0.0010$ \\
D61-180 & par 1 & $0.0187 \pm 0.0039$ & $0.938 \pm 0.059$ & $0.988 \pm 0.025$ \\
& par 2 & & $0.0083 \pm 0.0016$ & $0.975 \pm 0.057$ \\
& par 3 & \multirow{2}{*}{$0.0085 \pm 0.0021$} & $0.937 \pm 0.072$ & $0.0114 \pm 0.0025$ \\
D1-180 & par 1 & & $0.0070 \pm 0.0014$ & $0.954 \pm 0.067$ \\
& par 2 & & & $0.962 \pm 0.067$ \\
& par 3 & & & $0.0056 \pm 0.0014$ \\
\hline
\end{tabular}


Table 4. Estimates of direct genetic correlations between mortality traits.

\begin{tabular}{lll}
\hline & D15-60 & D61-180 \\
\hline D1-14 & $0.730 \pm 0.102$ & $0.343 \pm 0.120$ \\
D15-60 & & $0.537 \pm 0.129$ \\
\hline
\end{tabular}

parities. The residual correlations were all close to 0 , as they ranged from -0.010 to 0.018 . This means that the effect of repeated observations from the same dam was small. These estimates of genetic and residual correlations from model $\mathrm{C}$ justified the assumptions made in all the other models, where PM of calves born from dams with different parities was treated as the same trait, and the effect of repeated observations from the same dam was ignored.

Estimates of genetic correlations between the mortality traits from the bivariate analyses using model D are given in Table 4 . The estimated genetic correlation was high (0.73) between D1-14 and D15-60, moderateto-high (0.54) between D15-60 and D61-180, and low (0.34) between D1-14 and D61-180. All these genetic correlations were significantly different from 1 , indicating that different genes are responsible for early and late PM. The estimates of residual correlations were all very close to 0 , as they ranged from -0.003 to 0.005 . However, the interpretation of these residual correlations is not straightforward because only calves that survived the first period had an observation in later periods.

When the mortalities of males and females were treated as different traits using model $\mathrm{E}$, the estimated heritability of D1-14 and D15-60 were very similar for males and females (Table 5). For D1-180, the heritability on the observable scale was 0.009 and 0.006 for males and females, respectively. A larger difference between sexes was seen for D61-180, where the heritability on the observable scale was 0.015 for males and 0.004 for females. On the underlying scale, the heritabilities for D61-180 were 0.105 and 0.037, respectively. From model F, the heritability on the observable (and the underlying) scale for transferred males was 0.034
(0.187) and $0.008(0.064)$ for males that were not transferred (Table 6). Therefore, much of the difference in heritabilities of PM between sexes is because transferred males have a much higher heritability than nontransferred males. The genetic correlation between D61-180 for transferred and nontransferred males was very high (0.994), so genetically it must be the same mortality trait whether they were transferred or not. Only the magnitude of the genetic variation differed. The genetic correlations between different sexes were also high (>0.91) for all the mortality traits and did not deviate significantly from 1 .

Herd, herd-sex, and herd-year-seasons. Estimates from model B of the ratio of variance of herd, herd-sex, and herd-year-season to the phenotypic variance are given in Table 7. For D1-14 to D61-180, the ratio of the herd-sex variance increased from 0.001 to 0.005 . This means that management differences between sexes within the herd increased with increasing age of the calves. The ratio of variance for herd and herd-year-season ranged from 0.006 to 0.023 . Correlations between the effects of herd, herd-sex, and herdyear-seasons for D1-14, D15-60, and D61-180 were obtained from model D (Table 8). The effect of herd had moderate to high correlations between the traits $(0.64$ to 0.76 ), indicating that herds with low mortality in the first period also had low mortality in the later periods. Lower correlations ( 0.10 to 0.43 ) were estimated for the herd-year-season effect. This means that the effect of seasonal fluctuations within the herd on early PM has low associations with the effect of seasonal fluctuations within herd on late PM. The effect of herd-sex also had low correlations between early and late PM, ranging from -0.10 to 0.36 .

\section{Fixed Effects}

All estimates of fixed effects are from model B. Only the most interesting estimates are given and commented upon.

Seasonal effects. A visualization of the estimates of seasons showed that, in general, they followed the

Table 5. Estimates of genetic parameters from model E, in which each mortality trait is defined as different according to sex: direct heritabilities for males and females on the observed $\left(\mathrm{h}_{\mathrm{D}(\mathrm{o})}^{2}\right)$ and on the underlying scale $\left(\mathrm{h}_{\mathrm{D}(\mathrm{u})}^{2}\right)$ and estimates of direct genetic correlations $\left(\mathrm{r}_{\mathrm{g}}\right)$ between sex.

\begin{tabular}{lllllll}
\hline & \multicolumn{3}{c}{ Males } & & \multicolumn{3}{c}{ Females } \\
\cline { 2 - 3 } \cline { 5 - 6 } & $\mathrm{h}_{\mathrm{D}(\mathrm{o})}^{2}$ & $\mathrm{~h}_{\mathrm{D}(\mathrm{u})}^{2}$ & & $\mathrm{~h}_{\mathrm{D}(\mathrm{o})}^{2}$ & $\mathrm{~h}_{\mathrm{D}(\mathrm{u})}^{2}$ & $\mathrm{r}_{\mathrm{g}}$ \\
\hline $\mathrm{D} 1-14$ & $0.0025 \pm 0.0007$ & 0.015 & & $0.0033 \pm 0.0008$ & 0.024 & $0.952 \pm 0.054$ \\
$\mathrm{D} 15-60$ & $0.0017 \pm 0.0006$ & 0.014 & & $0.0013 \pm 0.0005$ & 0.013 & $0.963 \pm 0.081$ \\
$\mathrm{D} 61-180$ & $0.0145 \pm 0.0022$ & 0.105 & & $0.0040 \pm 0.0008$ & 0.037 & $0.911 \pm 0.055$ \\
$\mathrm{D} 1-180$ & $0.0090 \pm 0.0015$ & 0.030 & $0.0061 \pm 0.0011$ & 0.025 & $0.966 \pm 0.029$ \\
\hline
\end{tabular}


Table 6. Mean of D61-180 and estimates of genetic parameters from model F, in which D61-180 is defined as different traits for females, males not transferred (males-), and males transferred (males+): direct heritability on the observed $\left(\mathrm{h}_{\mathrm{D}(\mathrm{o})}^{2}\right)$, and direct heritability on the underlying scale $\left(\mathrm{h}_{\mathrm{D}(\mathrm{u})}^{2}\right)$ and genetic correlations $\left(r_{\mathrm{g}}\right)$.

\begin{tabular}{|c|c|c|c|c|c|}
\hline & Mean & $\mathrm{h}_{\mathrm{D}(\mathrm{o})}^{2}$ & $\mathrm{~h}_{\mathrm{D}(\mathrm{u})}^{2}$ & $\begin{array}{l}\mathrm{r}_{\mathrm{g}} \\
\text { Males- }\end{array}$ & $\begin{array}{l}\mathrm{r}_{\mathrm{g}} \\
\text { Males+ }\end{array}$ \\
\hline Females & 0.0168 & $0.0040 \pm 0.0008$ & 0.038 & $0.940 \pm 0.055$ & $0.900 \pm 0.063$ \\
\hline Males- & 0.0196 & $0.0076 \pm 0.0015$ & 0.064 & & $0.994 \pm 0.024$ \\
\hline Males+ & 0.0365 & $0.0343 \pm 0.0056$ & 0.187 & & \\
\hline
\end{tabular}

same pattern over regions. Therefore, these estimates were averaged over regions and weighed with the number of observations in each subclass. A seasonal effect for D1-14 seemed to exist, but no general trend could be detected for the other mortality traits. D1-14 of both females and males were lowest for calves born in the summer and highest for calves born in the winter (Figure 2). Depending on the year, the decline for D1-14 from winter to summer was from 0.005 to 0.010 for females and 0.010 to 0.015 for males. A tendency of higher D61-180 were seen for calves that were born in summer (which had their period of risk in the autumn), but there was a large variation from year to year.

Age of calving and parity. In general, the age at first calving and the parity of the dam had limited influence on PM of the calves (results not shown). The only exception was calves from dams with a low calving age (23 mo), which for all traits had a significantly higher mortality. For D1-180 the estimate of the effect of a calving age at 23 mo was 0.014 higher than for a calving age at $28 \mathrm{mo}$. Estimates of the effect of parity were all small and insignificant for all traits.

Calving interval. Calves from dams with calving intervals less than $331 \mathrm{~d}$ had a significantly higher frequency D1-180 (0.006) than calves from dams with a calving interval from 391 to $450 \mathrm{~d}$. The estimates of other calving intervals were not significant for any traits.

Twin. The estimates of the effect of having a twin brother or sister are given in Table 9 for male and female calves. A significantly higher PM for twin calves than for single-born calves was found for all the mortality traits and for all kinds of twins. The effects of twin-

Table 7. Estimates of ratios-of-variance components for herd, herdsex, and herd-year-season to the phenotypic variance from model B.

\begin{tabular}{llll}
\hline Trait & Herd & Herd-sex & Herd-year-season \\
\hline $\mathrm{D} 1-14^{1}$ & 0.011 & 0.001 & 0.010 \\
$\mathrm{D} 15-60^{1}$ & 0.011 & 0.003 & 0.009 \\
$\mathrm{D} 61-180^{1}$ & 0.006 & 0.005 & 0.009 \\
$\mathrm{D} 1-180^{1}$ & 0.023 & 0.012 & 0.015 \\
\hline
\end{tabular}

${ }^{1} \mathrm{SE}$ from 0.0003 to 0.0008 . ning for D1-14 relative to a single-born calf ranged from 0.010 to 0.024 , the effects for D15-60 ranged from 0.006 to 0.011 , and the effects for D61-180 ranged from 0.005 to 0.010 . For D1-180, the effect of being a twin ranged from 0.028 to 0.043 and was highest for males with a twin brother.

Transfer. The model for D61-180 accounted for the effect of transfers before the period of risk. Figure 3 shows the estimated effect of transfers at an age of 14 to 30 and 31 to $60 \mathrm{~d}$, depending on the month of the transfer. Calves transferred at 14 to 30 and 31 to $60 \mathrm{~d}$ of age had a significantly higher frequency of mortality than nontransferred calves, ranging from 0.011 to 0.021 and 0.006 to 0.030 , respectively. Calves transferred in the autumn had the highest mortality.

\section{DISCUSSION}

\section{Frequency}

The unadjusted frequency of mortality of Holsteins in Denmark was generally in accordance with other studies. From a Dutch study consisting of 859 Holstein female calves, the frequency of PM was 0.049 from birth to 4 mo of age (Perez et al., 1990). Higher frequencies were found in American studies of Holstein calves: Losinger and Heinrichs (1997) found a frequency of 0.094 from birth to weaning for 47,057 female calves, and Sivula et al. (1996) found a frequency of 0.08 per 100 $\mathrm{d}$ at risk in a study of 845 female calves. In the study

Table 8. Estimates of correlations between effects of herd, herd-sex, and herd-year-seasons from model D.

\begin{tabular}{lrrr}
\hline & & D1-14 & D15-60 \\
\hline Herd $^{1}$ & D15-60 & 0.750 & \\
& D61-180 & 0.635 & 0.760 \\
Herd-sex $^{2}$ & D15-60 & 0.286 & \\
Herd-year-season $^{3}$ & D61-180 & -0.103 & 0.356 \\
& D15-60 & 0.344 & \\
& D61-180 & 0.102 & 0.427 \\
\hline
\end{tabular}

${ }^{1} \mathrm{SE}$ from 0.024 to 0.036 .

${ }^{2} \mathrm{SE}$ from 0.073 to 0.111 .

${ }^{3} \mathrm{SE}$ from 0.032 to 0.035 . 
Females

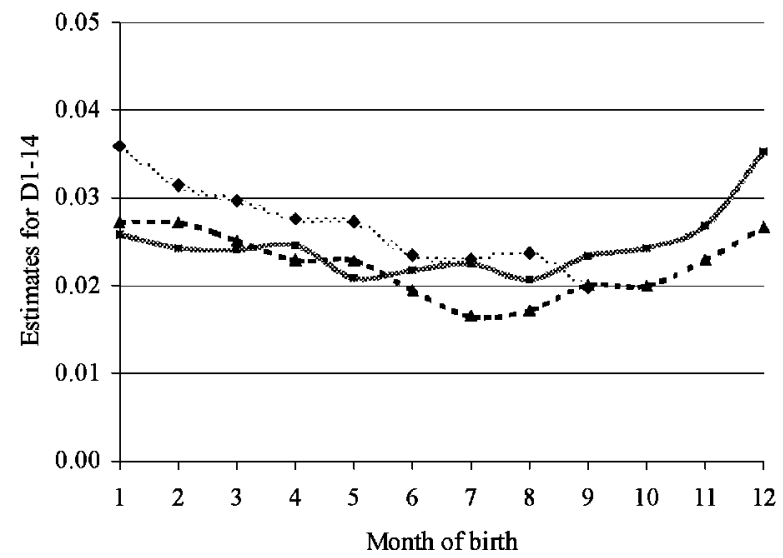

Males

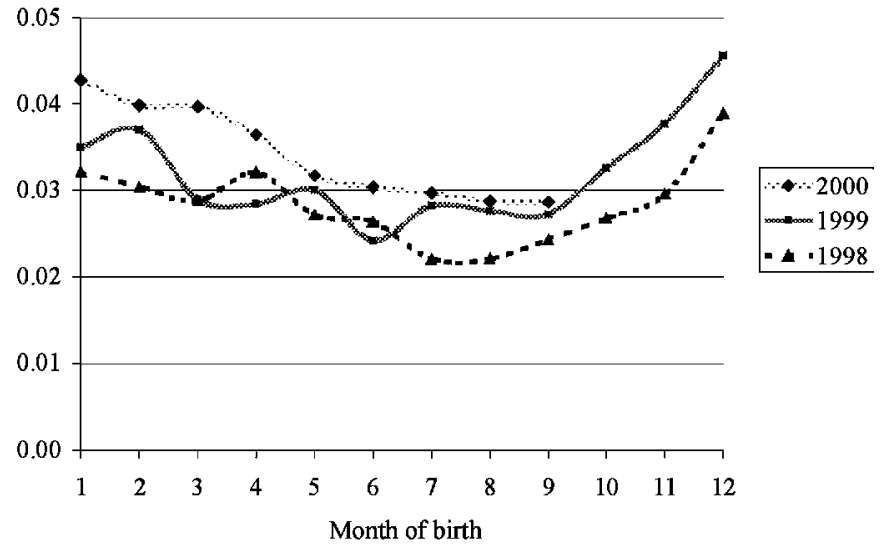

Figure 2. Estimates for D1-14 of the effect of birthyear-birthmonth-region-sex for a single-born female and male calf from a second calving dam with a calving interval from 331 to 390 d. Estimates are averaged over regions.

of Olsson et al. (1993), based on 6164 Swedish Red and White and Swedish Holstein calves, the frequency of $\mathrm{PM}$ in the period from 0 to $90 \mathrm{~d}$ after birth was 0.026 , which is somewhat lower than that found in the present study. Simensen (1982) also reported a low frequency (0.012) of PM from 1 to $30 \mathrm{~d}$ of age from 6285 Norwegian Red calves. As the genetic variation of PM is small, the differences between the studies are believed to arise from differences in management, climate, and housing between the countries.

\section{Genetic Variation}

Only two other studies reporting estimated genetic variation of PM were found in the literature. From 5782 single-born Brown Swiss calves, Erf et al. (1990) estimated a direct heritability of 0.008 on the observable scale and 0.044 on the underlying scale for early PM (d 1 to 7 ). In a study of 4639 calves from Hereford and Angus dams mated with sires from 14 different breeds, the heritability on the observable scale of survival from birth to weaning (approximately $200 \mathrm{~d}$ ) were $0.067 \pm$
0.097 within breed and $0.114 \pm 0.086$ among breeds (Cundiff et al., 1986). These studies agree with the findings in the present study that direct heritability seems to be larger for late PM than for early PM. Heritabilities of respiratory disease for beef calves during the preweaning and postweaning periods have been estimated at $0.10 \pm 0.02$ and $0.06 \pm 0.07$ on the observable scale (Muggli-Cockett et al., 1992). From Danish performance stations, where potential AI-bulls are reared, the heritability of the number of respiratory diseases and all diseases in the period from 42 to $336 \mathrm{~d}$ of age has been estimated to $0.29 \pm 0.03$ and $0.28 \pm 0.03$, respectively, for Danish Holstein (Wassmuth et al., 2000). These findings indicate that resistance to calfhood diseases is heritable. Estimates of genetic correlations between calfhood diseases and PM have not been found in the literature.

It is interesting to note that the heritability of D61180 (and the genetic variation) was much higher for the transferred calves than for calves that were not transferred. Transferred calves are usually allocated in pens with calves from other herds. Thereby, transferred

Table 9. Estimates for the effect of being a twin. Estimates for males are relative to the effect of a singleborn male and estimates for females are relative to the effect of a single-born female.

\begin{tabular}{lllll}
\hline Trait & $\begin{array}{l}\text { Male with } \\
\text { twin brother }\end{array}$ & $\begin{array}{l}\text { Male with } \\
\text { twin sister }\end{array}$ & $\begin{array}{l}\text { Female with } \\
\text { twin brother }\end{array}$ & $\begin{array}{l}\text { Female with } \\
\text { twin sister }\end{array}$ \\
\hline $\mathrm{D} 1-14^{1}$ & 0.024 & 0.010 & 0.013 & 0.018 \\
$\mathrm{D} 15-60^{1}$ & 0.010 & 0.009 & 0.011 & 0.006 \\
$\mathrm{D} 1-181^{1}$ & 0.008 & 0.010 & 0.008 & 0.005 \\
$\mathrm{D} 1-180^{2}$ & 0.043 & 0.028 & 0.033 & 0.028 \\
\hline
\end{tabular}

${ }^{1} \mathrm{SE}$ from 0.0014 to 0.0023 .

${ }^{2} \mathrm{SE}$ from 0.0024 to 0.0035 . 


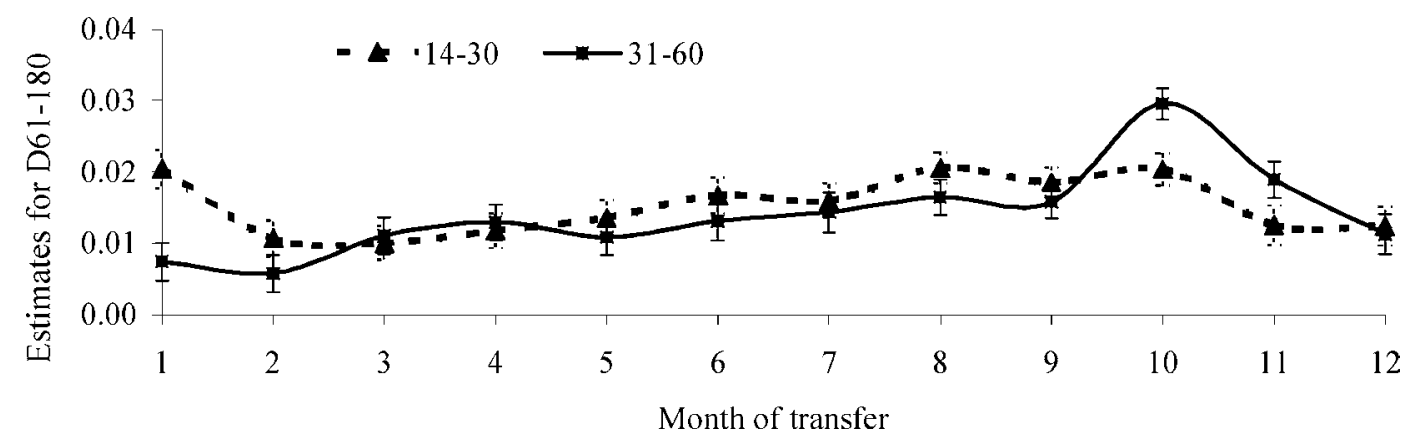

Figure 3. Estimates and standard errors of the effect of transfers in the period 14 to 30 and 31 to $60 \mathrm{~d}$ after birth for D61-180 depending on the month of transfer. Estimates are relative to a calf that was not transferred.

calves are exposed to a wider range of pathogens and to a higher pressure of infections than calves that are not transferred. This might give a broader challenge to the immune system of the transferred calves, and thus they express a higher genetic variation. The results of Wassmuth et al. (2000) were also based on calves from different herds that had been transferred to the breeding station. The findings in the present study indicate that the heritabilities of calfhood diseases might be lower if the data were from calves that are not transferred.

A question to be answered is whether the same genes affect early PM and stillbirth. Erf et al. (1990) estimated the genetic association between early mortality ( $\mathrm{d} 1$ to 7 ) and stillbirth and found a rank correlation of 0.55. However, it was based on 86 sires only.

\section{Season}

Menzies et al. (1996) found increased mortality associated with respiratory diseases of 1 - to 5-mo-old calves in December and January. They associated the higher frequency of respiratory diseases with humid weather in this period. As autumn and winter in Denmark are generally humid, it could explain some of the seasonal effects in this study. But the lower frequency of early PM must be caused by other factors, as respiratory diseases are not the primary cause of early PM. Calving ease is a factor not included in this study, which is found to affect early PM (Azzam et al., 1993; Wells et al., 1996). As calving problems in Denmark (Pedersen, 25/04/2002, personal communication.) and France (Manfredi et al., 1991a) are reduced in the summer, this could explain some of the seasonal effects on early PM seen in this study.

\section{Transfer}

Transfers of calves during the period of risk were not accounted for in the analyses. In initial studies, the effect of transfers during the period of risk were included in the model. However, the effect of transfers during the period of risk was confounded with the fact that they had survived until they were transferred. Therefore, we chose to account for transfers before the period of risk only. The effect of the second herd was not accounted for. Seen in retrospect, including the effect of the herd they were transferred to would presumably have improved the model for D61-180.

For D61-180, the estimated effect of being transferred in the periods of 14 to 30 and 31 to $60 \mathrm{~d}$ of age was at the same level. However, it should be noted that early transferred calves that die immediately after the transfer were not included in D61-180. Only calves that were alive at d 60 were included. As the effect of transfer is expected to be highest immediately after the transfer, early transfers must have a larger impact on the overall mortality than later transfers. The reason for the effect of transfers could be that transferred calves are exposed to more stress and to an increased pressure of infections than calves that are not transferred. This will increase the incidence.

\section{Statistical Methods}

Estimation of genetic correlations between early and late mortality was an important aim of this study. Therefore, linear models were chosen because efficient algorithms for the analysis of large datasets with linear multivariate models were available in existing software (Jensen et al., 1997). Another possibility would be to use threshold models and estimate the effects on an underlying scale (Gianola, 1982). Gates et al. (1999) stated that the genetic correlations between two binary traits estimated with linear models in theory should be unbiased, though their simulations studies showed that estimates of genetic correlation in general tended to be biased downwards. This was particularly the case when confounding existed between herds and sires. In this dataset, only AI-sires were used, so no confounding be- 
tween herd and sires was expected. Also practical applications of linear models on binary data from dairy cattle with large progeny groups have shown only small differences between linear and threshold models in the prediction of breeding values of sires (Weller and Gianola, 1989; Heringstad et al., 1997). If further knowledge about environmental effects is desired, survival analyses would presumably be a better method than linear models (e.g., the effect of transfers could be fitted as a time-dependent effect). Modelling a genetic effect of the sire is also possible with survival analyses (Ducrocq and Sölkner, 1998), but this approach assumes a constant effect of sire through time. Taking account of a genetic correlation less than unity for early and late PM could be done by making the sire effect time-dependent, but this approach still needs development (Ducrocq, 1999).

\section{Implications}

If $\mathrm{PM}$ is found to be of (economic) importance relative to other traits, PM could be included in a breeding program for dairy cattle. It is possible to gain fairly reliable predictions of breeding values, as the number of offspring per proven sire in general will be high. Using selection index theory in the program SIP (Wagenaar et al., 1995) a typical Danish bull will obtain a correlation between the predicted breeding value of D1180 and the true breeding value of 0.64 . This was based on a heritability of 0.007 for D1-180, information from 250 offspring, and information from 2000 offspring for the sire of the bull. If transfers of calves become more common, the importance of including PM in a breeding program will increase, as PM of transferred calves showed higher genetic variation than calves that were not transferred. However, if PM is not included directly in the breeding goal, it may still be valuable to estimate breeding values of PM. These breeding values could be used for monitoring the population in order to identify extreme bulls, to document the genetic development of the trait, and to identify QTL affecting PM.

\section{CONCLUSIONS}

This study has shown that direct genetic variation for PM exists and suggests that different genes affect early and late PM. Maternal genetic variation of postnatal mortality was found to be very small and could not be detected for PM after d 14. Postnatal mortality of calves from dams with different parities appears to be genetically the same trait. On the observable scale, the direct heritabilities ranged from 0.0014 to 0.0077 and were highest for late PM (D61-180). Postnatal mortality for males and females had a very high genetic correlation that was not significantly different from 1 . The direct heritability of D61-180 was highest for males. This was primarily due to the fact that $28 \%$ of the males were transferred to another herd. These transferred males showed a much higher heritability than nontransferred males. If transfers of calves become more common, the importance of including PM in a breeding program will increase.

\section{REFERENCES}

Agerholm, J. S., A. Basse, H. V. Krogh, K. Christensen, and L. Rønsholt. 1993. Abortion and calf mortality in Danish cattle herds. Acta Vet. Scand. 34:371-377.

Azzam, S. M., J. E. Kinder, M. K. Nielsen, L. A. Werth, K. E. Gregory, L. V. Cundiff, and R. M. Koch. 1993. Environmental effects on neonatal mortality of beef calves. J. Anim Sci. 71:282-290.

Cundiff, L. V., M. D. MacNeil, K. E. Gregory, and R. M. Koch. 1986. Between- and within-breed genetic analysis of calving traits and survival to weaning in beef cattle. J. Anim. Sci. 63:27-33.

Dempster, E. R., and I. M. Lerner. 1950. Heritability of threshold characters. Genetics 35:212-236.

Ducrocq, V. 1999. Topics that may deserve further attention in survival analysis applied to dairy cattle breeding-some suggestions. Interbull Bull. 21:181-189.

Ducrocq, V., and J. Sölkner. 1998. "The survival kit_V3.0” A package for large analysis of survival data. Proc 6th World Cong. Genet. Appl. Livest. Prod. 27:445-446.

Erf, D. F., L. B. Hansen, and R. R. Neitzel. 1990. Inheritance of calf mortality for Brown Swiss cattle. J. Dairy Sci. 73:1130-1134.

Gates, P., K. Johansson, and B. Danell. 1999. Quasi-REML correlation estimates between production and health traits in the presence of selection and confounding: A simulation study. J. Anim. Sci. 77:558-568.

Gianola, D. 1982. Theory and analysis of threshold characters. J. Anim. Sci. 54:1079-1096.

Harvey, Q. R. 1982. Least-squares analysis of discrete data. J. Anim. Sci. 54:1067-1071.

Heringstad, B., A. Karlsen, G. Klemetsdal, and J. Ruane. 1997. Preliminary results from a genetic analysis of clinical mastitis data. Interbull Bull.15:45-49.

Jensen, J., and P. Madsen. 1994. DMU. A package for the analysis of multivariate mixed models. Proc. 5th World Congress on Genet. Appl. Livest. Prod. Comput. Strat. Software 22:45-46.

Jensen, J., E. A. Mäntysaari, P. Madsen, and R. Thompson. 1997. Residual maximum likelihood estimation of (co)variance components in multivariate mixed linear models using average information. J. Ind. Soc. Ag. Stat. 49:215-236.

Kaplan, E. L., and P. Meier. 1958. Nonparametric estimation from incomplete observations. J. Am. Stat. Assoc. 53:457-481.

Losinger, W. C., and A. J. Heinrichs. 1997. Management practices associated with high mortality among preweaned dairy heifers. J. Dairy Res. 64:1-11.

Manfredi, E. J., V. Ducrocq, and J. L. Foulley. 1991a. Genetic analysis of dystocia in dairy cattle. J. Dairy Sci. 74:1715-1723.

Manfredi, E. J., M. San Cristobal, and J. L. Foulley. 1991b. Some factors affecting the estimation of genetic parameters for cattle dystocia under a threshold model. Anim. Prod. 53:151-156.

Menzies, F. D., D. G. Bryson, T. McCallion, and D. I. Matthews. 1996. Mortality in cattle up to two years old in Northern Ireland during 1992. Vet. Rec. 138:618-622.

Muggli-Cockett, N. E., L. V. Cundiff, and K. E. Gregory. 1992. Genetic analysis of bovine respiratory disease in beef calves during the first year of life. J. Anim. Sci. 71:2013-2019.

Olesen, I., A. F. Groen, and B. Gjerde. 2000. Definition of animal breeding goals for sustainable production systems. J. Anim. Sci. 78:570-582.

Olsson, S.-O., S. Viring, U. Emanuelsson, and S.-O. Jacobsson. 1993. Calf diseases and mortality in Swedish dairy herds. Acta Vet. Scand. 34:263-269. 
Perez, E., J. P. T. M. Noordhuizen, L. A. Van Wijkhuise, and E. N. Stassen. 1990. Management factors related to calf morbidity and mortality rates. Livest. Prod. Sci. 25:79-93.

SAS, 1999. SAS OnlineDoc Version 8. SAS Inst., Inc., Cary, NC.

Schmitz, F., R. W. Everett, and R. L. Quaas. 1991. Herd-year-season clustering. J. Dairy Sci. 74:629-636.

Shook, G. E. 1998. Calfhood disease: An assessment. Proc. 6th World Cong. Genet. Appl. Livest. Prod., Armidale, Australia 23:379-382.

Simensen, E. 1982. An epidemiological study of calf health and performance in Norwegian dairy herds. Acta Agric. Scand. 32:411-419.

Sivula, N. J., T. R. Ames, W. E. Marsh, and R. E. Wedin. 1996. Descriptive epidemiology of morbidity and mortality in Minnesota dairy heifer calves. Prev. Vet. Med. 27:155-171.
Van Vleck, L. D. 1972. Estimation of heritability of threshold characters. J. Dairy Sci. 55:218-225.

Wagenaar, D., J. A. M. Van Arendonk, and M. Kramer. 1995. Selection Index Program (SIP) User Manual. Wageningen Agricultural University, The Netherlands.

Wassmuth, R., D. Boelling, P. Madsen, J. Jensen, and B. B. Andersen. 2000. Genetic parameters of beef production traits and disease incidence of growing bulls. Acta Agric. Scand. Sect. A. Animal Sci. 50:103-110.

Weller, J. I., and D. Gianola. 1989. Models for genetic analysis of dystocia and calf mortality. J. Dairy Sci. 72:2633-2643.

Wells, S. J., D. A. Dargatz, and S. L. Ott. 1996. Factors associated with mortality to 21 days of life in dairy heifers in the United States. Prev. Vet. Med. 29:9-19. 